\title{
AVALIAÇÃO NUTRICIONAL EM FOLHAS DE BANANEIRA 'PRATA-ANÃ' ADUBADAS COM COMPOSTO ORGÂNICO ${ }^{1}$
}

\author{
ERVAL RAFAEL DAMATTO JUNIOR ${ }^{2}$, ROBERTO LYRA VILLAS BÔAS ${ }^{3}$, SARITA LEONEL ${ }^{4}$, \\ DIRCEU MAXIMINO FERNANDES ${ }^{5}$
}

\begin{abstract}
RESUMO - Desenvolveu-se o presente trabalho objetivando avaliar o estado nutricional de plantas cultivadas com diferentes doses de composto orgânico no primeiro ciclo de produção da bananeira 'Prata-Anã', cultivada em Botucatu-SP. Os tratamentos empregados foram constituídos de diferentes doses de composto orgânico: $\mathrm{T} 1=0 \mathrm{~g}$ de $\mathrm{K}_{2} \mathrm{O} / \mathrm{planta}$ (Testemunha); T2 = 98,5 g de $\mathrm{K}_{2} \mathrm{O} / \mathrm{planta}$ (43 kg de composto/planta); T3=197,0 g de $\mathrm{K}_{2} \mathrm{O} /$ planta ( $86 \mathrm{~kg}$ de composto/planta); $\mathrm{T} 4=290,5 \mathrm{~g}$ de $\mathrm{K}_{2} \mathrm{O} /$ planta $\left(129 \mathrm{~kg}\right.$ de composto/planta), e $\mathrm{T} 5=394,0 \mathrm{~g}$ de $\mathrm{K}_{2} \mathrm{O} / \mathrm{planta}(172 \mathrm{~kg}$ de composto/planta), sendo as doses de composto calculadas de acordo com o teor de potássio presente no mesmo. Adotou-se o delineamento experimental de blocos casualizados, composto de 5 tratamentos, 5 repetições e 2 plantas por parcela. Os dados foram submetidos à análise de variância e à análise de regressão. Os efeitos da adubação orgânica foram avaliados por meio de análises químicas de macro e micronutrientes nas folhas, durante o florescimento e na colheita. A adubação orgânica não promoveu diferença nas concentrações de nutrientes nas folhas, contudo verificou-se que os teores foliares de potássio, considerados adequados para a bananeira 'Prata-Anã', podem ser inferiores aos padrões atualmente adotados para a cultura.
\end{abstract}

Termos para indexação: Musa sp., banana, 'Prata-Anã', adubação orgânica, nutrição, potássio.

\section{NUTRITIONAL LEAVES EVALUATION OF BANANA ‘PRATA-ANÃ' WITH ORGANIC COMPOST}

ABSTRACT - The present work was carried out aiming to evaluate nutritional plants conditions with different organic compost rates in the first production cycle of banana 'Prata Anã' in Botucatu-SP. Different organic compost rates were used for the treatments: T1 $=0 \mathrm{~g}$ of $\mathrm{K}_{2} \mathrm{O} / \mathrm{plant}(\mathrm{zero}$ of the compost); $\mathrm{T} 2=98,5 \mathrm{~g}$ of $\mathrm{K}_{2} \mathrm{O} /$ plant $(43 \mathrm{~kg}$ of the compost $/$ plant $) ; \mathrm{T} 3=197,0 \mathrm{~g}$ of K $2 \mathrm{O} /$ plant $(86 \mathrm{~kg}$ of the compost/plant $) ; \mathrm{T} 4=290,5 \mathrm{~g}$ of K $2 \mathrm{O} / \mathrm{plant}$ ( $129 \mathrm{~kg}$ of the compost/plant ); and $\mathrm{T} 5=394,0 \mathrm{~g}$ of $\mathrm{K}_{2} \mathrm{O} / \mathrm{plant}$ (172 $\mathrm{kg}$ of the compost/plant). The compost rates were calculated based on the quantity of potassium contained in the compost. The experiment was arranged in randomized blocks design, with 5 treatments, 5 replications and 2 plants per plot. The obtained data were submitted to variance analyses and to regression analyses. The effects of organic fertilization were evaluated by chemical leaves analyses of macro and micro nutrients during blooming and harvest. The organic fertilization didn't provide differences in leaves nutrients concentration of banana 'Prata Anã'. Therefore it was observed that the potassium contents in the leaves, considered appropriate to 'Prata-Anã' banana, could be smaller than the ones recommended to the culture.

Index terms: Musa sp., banana, 'Prata-Anã', organic fertilization, nutrition, potassium.

\section{INTRODUÇÃO}

A bananeira é muito exigente em nutrientes, principalmente potássio e nitrogênio. No entanto, ocorrem diferenças entre cultivares e até mesmo dentro de um grupo genômico nas quantidades absorvidas, em razão das características genéticas, dos teores de nutrientes no solo, do tipo de manejo, entre outros (Borges et al., 2000). É uma cultura que extrai grandes quantidades de nutrientes por hectare, sendo a adubação um dos fatores que mais influencia na quantidade e qualidade da produção, bem como na resistência a doenças (Carvalho et al., 1986). Portanto, a diagnose foliar em época adequada pode auxiliar na recomendação das adubações, bem como suprir deficiências nutricionais em determinados momentos do ciclo da cultura.

A adubação e a calagem devem ser feitas baseadas nos resultados da análise do solo e foliar. Os estádios fisiológicos são importantes para a adubação em cobertura, pois, durante o ciclo, há períodos de maior demanda pelos nutrientes, como, por exemplo, no crescimento vegetativo e no "lançamento" do cacho. Nessas fases, ocorrem maiores demandas de nitrogênio, enquanto por ocasião da "engorda" dos frutos é maior a demanda por potássio (Moreira, 1987). Além da adubação química, a orgânica também promove muitos benefícios, melhorando as propriedades físicas (aeração, densidade, porosidade, retenção e infiltração de água) e a biologia do solo, promovendo maior diversidade de microorganismos, e causando modificações em características químicas, como alterações na CTC e $\mathrm{pH}$, e no fornecimento de nutrientes. Borges et al. (2002) observaram efeitos positivos da adubação orgânica em bananeiras, em que o uso de esterco como fonte de adubo para as plantas promoveu aumento no número e comprimento de frutos por cacho.

Para uma adequada diagnose foliar, diversos fatores que interferem nos teores de nutrientes nas folhas de bananeira, devem ser levados em consideração. Martin-Prevél (1977) classifica esses em: fatores internos, como cultivar, estádio fenológico das plantas, posição e porção das folhas e externos, como clima, solo, parasitismo e tratos culturais.

Níveis adequados de nutrientes em folhas, das mais diversas cultivares de bananeira, ainda não foram estabelecidos, mas vários autores admitem faixas adequadas para macro e micronutrientes para algumas cultivares em diversas condições (Jones Jr. et al., 1991; Robinson, 1986; Ribeiro et al., 1999; Prezotti, 1992; Raij et al., 1997). O presente trabalho objetivou avaliar o estado nutricional das plantas cultivadas com diferentes doses de composto orgânico no primeiro ciclo de produção da bananeira 'Prata-Anã', cultivada nas condições de Botucatu-SP.

\section{MATERIALEMÉTODOS}

O experimento foi instalado na Faculdade de Ciências

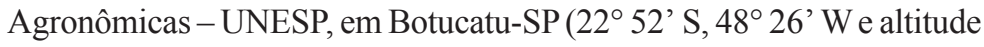
$786 \mathrm{~m}$ ), com clima temperado quente (mesotérmico), com chuvas no verão e seca no inverno (Cwa - Koppen) e temperatura média mais quente superior a $22^{\circ} \mathrm{C}$ (Cunha et al., 1999). O solo da área foi classificado como Nitossolo Vermelho (Embrapa, 1999).

Instalou-se o experimento em novembro de 2002, com mudas

\footnotetext{
(Trabalho 156/2005). Recebido: 03/10/2005. Aceito para publicação: 30/03/2006.

${ }^{2}$ Eng. Agr. Doutorando em Horticultura da Faculdade de Ciências Agronômicas/UNESP. Depto. de Recursos Naturais/Solos, Cep: 18610-307 - Botucatu-SP. Email: ervaljr@fca.unesp.br. Bolsista Fapesp.

${ }^{3}$ Prof. Dr. do Depto. de Recursos Naturais - Solos da Faculdade de Ciências Agronômicas/UNESP, Cep: 18610-307 - Botucatu-SP. E-mail: rlvboas@fca.unesp.br. ${ }^{4}$ Prof $^{\mathrm{a}}$. Dr ${ }^{\mathrm{a}}$. do Depto. de Produção Vegetal - Horticultura da Faculdade de Ciências Agronômicas/UNESP, Cep: 18610-307 - Botucatu-SP. E-mail: sarinel@fca.unesp.br. ${ }^{5}$ Prof. Dr. do Depto. de Recursos Naturais - Solos da Faculdade de Ciências Agronômicas/UNESP, Cep: 18610-307 - Botucatu-SP. E-mail: dmfernandes@fca.unesp.br.
} 
convencionais da cv. Prata-Anã, adotando-se o espaçamento de 2,5m entre linhas e $2,5 \mathrm{~m}$ entre plantas. Adotou-se o sistema de irrigação localizada (microaspersão), com vazão de emissores de $40 \mathrm{~L} / \mathrm{h}$. O solo apresentava, na camada de 0 a $20 \mathrm{~cm}$, as seguintes características químicas: $\mathrm{pH}\left(\mathrm{CaCl}_{2}\right)=5,9 ; \mathrm{MO}=28 \mathrm{~g} / \mathrm{dm}^{3} ; \mathrm{P}($ resina $)=102 \mathrm{mg} / \mathrm{dm}^{3} ; \mathrm{H}$ $+\mathrm{Al}=31 \mathrm{mmol} / \mathrm{dm}^{3} ; \mathrm{K}=4,2 \mathrm{mmol} / \mathrm{dm}^{3} ; \mathrm{Ca}=65 \mathrm{mmol} / \mathrm{dm}^{3} ; \mathrm{Mg}=22$ $\mathrm{mmol} / \mathrm{dm}^{3} ; \mathrm{SB}=91 \mathrm{mmol} / \mathrm{dm}^{3} ; \mathrm{CTC}=122 \mathrm{mmol}_{\mathrm{c}} / \mathrm{dm}^{3} ; \mathrm{V}(\%)=75 \% ; \mathrm{B}=$ $0,19 \mathrm{mg} / \mathrm{dm}^{3} ; \mathrm{Cu}=3,8 \mathrm{mg} / \mathrm{dm}^{3} ; \mathrm{Fe}=23 \mathrm{mg} / \mathrm{dm}^{3} ; \mathrm{Mn}=11,6 \mathrm{mg} / \mathrm{dm}^{3} ; \mathrm{Zn}=$ $2,3 \mathrm{mg} / \mathrm{dm}^{3}$.

Os tratamentos empregados foram constituídos de diferentes doses de composto orgânico: $\mathrm{T} 1=0 \mathrm{~g}$ de $\mathrm{K}_{2} \mathrm{O} /$ planta (dose zero do composto - Testemunha); $\mathrm{T} 2=98,5 \mathrm{~g}$ de $\mathrm{K}_{2} \mathrm{O} /$ planta $(43 \mathrm{~kg}$ de composto/ planta); $\mathrm{T} 3=197,0 \mathrm{~g}$ de $\mathrm{K}_{2} \mathrm{O} /$ planta $(86 \mathrm{~kg}$ de composto $/$ planta); $\mathrm{T} 4=$ 290,5 g de $\mathrm{K}_{2} \mathrm{O} /$ planta (129 $\mathrm{kg}$ de composto/planta ); $\mathrm{T} 5=394,0 \mathrm{~g}$ de $\mathrm{K}_{2} \mathrm{O} /$ planta (172 kg de composto/planta), sendo as doses de composto calculadas de acordo com o teor de potássio presente no composto. A adubação anual, utilizando o composto produzido a partir de serragem de madeira e esterco bovino como fonte de nutrientes, foi dividida em 5 parcelas, aplicadas a cada dois meses, nas quantidades determinadas para cada tratamento. O composto empregado como fonte de nutrientes apresentava as seguintes características: $\mathrm{pH}=7,50$; relação $\mathrm{C} / \mathrm{N}=25 / 1$; $\mathrm{Um}=62 \% ; \mathrm{MO}=77 \%$. Em porcentagem, apresentou: $\mathrm{N}=1,75 ; \mathrm{P}_{2} \mathrm{O}_{5}=$ 1,$44 ; \mathrm{K}_{2} \mathrm{O}=0,60 ; \mathrm{Ca}=1,96 ; \mathrm{Mg}=0,33 ; \mathrm{S}=0,30 ; \mathrm{C}=42,78 ;$ e em mg kg ${ }^{1}: \mathrm{Fe}=2450 ; \mathrm{Cu}=56 ; \mathrm{Mn}=114 ; \mathrm{Na}=1600 ; \mathrm{Zn}=112$.

O delineamento experimental adotado foi em blocos casualizados, com 5 tratamentos, 5 repetições e 2 plantas por parcela. Os dados foram submetidos à análise de variância e, para os parâmetros considerados significativos pelo teste $\mathrm{F}$, à análise de regressão.

Nas fases de inflorescência e de colheita dos frutos, retiraramse amostras foliares de duas plantas úteis por parcela, coletadas da $3^{\text {a }}$ folha a partir do ápice. Foram utilizados $10 \mathrm{~cm}$ da parte interna mediana do limbo foliar, eliminando-se a nervura central, conforme recomendações da norma internacional (Martin-Prével, 1984). As folhas foram lavadas e secas em estufa a $65^{\circ} \mathrm{C}$ e encaminhadas ao Laboratório de Nutrição Mineral de Plantas do Departamento de Recursos Naturais - Solo, onde se realizou a análise química, segundo metodologia descrita por Malavolta et al. (1997). Foram analisados os teores de nitrogênio, fósforo, potássio, cálcio, magnésio, enxofre, boro, cobre, ferro, manganês e zinco.

\section{RESULTADOS E DISCUSSÃO}

Avaliaram-se os teores nutricionais no momento do florescimento, objetivando verificar alguma deficiência que pudesse comprometer a produção, uma vez que há padrões gerais para a cultura. Já a avaliação nutricional no momento da colheita dos frutos foi realizada objetivando verificar se havia alterações na concentração de nutrientes, pois as folhas, como o pseudocaule, após o corte da planta, são mantidos no solo e podem liberar esses nutrientes quando se decompõem.

Os teores de nutrientes na massa seca foliar da bananeira 'PrataAnã', mostraram a seguinte ordem de concentração no florescimento das plantas: $\mathrm{K}>\mathrm{N}>\mathrm{Ca}>\mathrm{Mg}>\mathrm{S}>\mathrm{P}$. No momento da colheita, os teores mantiveram a mesma ordem, exceto o $\mathrm{N}$ que se igualou ao $\mathrm{K}$ $(\mathrm{K}=\mathrm{N}>\mathrm{Ca}>\mathrm{Mg}>\mathrm{S}>\mathrm{P})$.

Os teores de nitrogênio e fósforo determinados nas folhas da bananeira Prata-Anã encontravam-se, segundo os padrões nutricionais conhecidos (Raij et al., 1997), adequados no momento do florescimento (Tabela 1), não havendo diferenças entre tratamentos. No momento da colheita dos frutos, os teores destes dois nutrientes diminuíram, efeito esse causado possivelmente pela translocação aos frutos, não sendo observada diferença entre os tratamentos.

Os teores de potássio nas folhas, no momento do

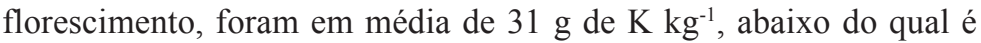
sugerido por Raij et al. (1997), porém, em nenhum momento, foram observados sintomas de deficiência desse nutriente nas plantas. $\mathrm{Na}$ colheita, houve diminuição acentuada nos teores de potássio nas folhas, como pode ser observado na Tabela 1 .

Resultados semelhantes foram observados por Fontes et al. (2003), no momento da formação do cacho, em que os teores de potássio foram menores que os observados no florescimento. Os autores justificam isso devido à translocação deste nutriente das folhas para o cacho em formação, que, neste momento, passa a ser o dreno principal da planta. Segundo Lahav \& Turner (1983), o potássio é o nutriente mais encontrado nos frutos de bananeira, com isso sua exigência tornase maior na época de formação do cacho. Gomes (2004), aplicando doses de potássio via fertirrigação, não observou diferença nos teores foliares de potássio. A exemplo deste trabalho, o autor encontrou teores médios de $27 \mathrm{~g} \mathrm{~kg}^{-1}$ de potássio nas folhas, abaixo dos citados por Raij et al. (1997), com produção de 17 t ha ${ }^{-1}$ para a bananeira 'Prata-Anã'. Guerra (2001), trabalhando com fertirrigação em bananeira 'Prata-Anã', notou que os teores foliares de potássio estavam abaixo dos níveis adequados para a bananeira. Resultados semelhantes foram encontrados por Teixeira (2000) em um mesmo tipo de solo e sob irrigação.

Diante dos resultados obtidos no trabalho, semelhantes aos de Gomes (2004), Guerra (2001) e Teixeira (2000), é possível sugerir que, para a bananeira 'Prata-Anã', a faixa adequada de potássio está entre 25 e $30 \mathrm{~g} \mathrm{~kg}^{-1}$. Malavolta (1979) sugere que o teor foliar adequado para bananeira seria $27 \mathrm{~g} \mathrm{~kg}^{-1}$ e que, apenas abaixo de $20 \mathrm{~g} \mathrm{~kg}^{-1}$, as folhas seriam consideradas deficientes. Para Prezotti (1992) e Raij et al. (1997), a faixa de concentração de potássio em folhas de bananeira deve estar entre 32 e $54 \mathrm{~g} \mathrm{~kg}^{-1}$, enquanto Robinson (1986) cita ser esta faixa mais estreita (31 a $40 \mathrm{~g} \mathrm{~kg}^{-1}$ ), Ribeiro et al. (1999) citam como teor adequado 28 $\mathrm{g} \mathrm{kg}^{-1}$ e Jones Jr. et al. (1991), 38 a $50 \mathrm{~g} \mathrm{~kg}^{-1}$. Portanto, a indicação de teores adequados de potássio em folhas de bananeira é bastante variável, sugerindo estudos de teores adequados de nutrientes nas folhas de bananeira específicos para as cultivares.

É interessante observar que os teores de potássio não se alteraram entre a testemunha e a dose mais elevada de composto, indicando que, se ocorreu a chamada "absorção de luxo", o potássio não permaneceu na folha, sendo translocado para outros órgãos ou até mesmo para as outras plantas da família.

Os teores de cálcio nas folhas, no momento do florescimento

TABELA 1 - Teores médios de macronutrientes em folhas de bananeira 'Prata-Anã', no florescimento e na colheita dos frutos ( $\left.\mathrm{g} \mathrm{kg}{ }^{-1}\right)$.

\begin{tabular}{|c|c|c|c|c|c|c|c|c|c|c|c|c|}
\hline \multirow[t]{2}{*}{ Tratamentos } & \multicolumn{2}{|c|}{ Nitrogênio } & \multicolumn{2}{|c|}{ Fósforo } & \multicolumn{2}{|c|}{ Potássio } & \multicolumn{2}{|c|}{ Cálcio } & \multicolumn{2}{|c|}{ Magnésio } & \multicolumn{2}{|c|}{ Enxofre } \\
\hline & Flor. & Colh. & Flor. & Colh. & Flor. & Colh. & Flor. & Colh. & Flor. & Colh. & Flor. & Colh. \\
\hline T1: 0 kg composto/planta & 30 & 21 & 2,1 & 1,5 & 31 & 22 & 9 & 12 & $3,3 \mathrm{ab}$ & 4,1 & 2,6 & 1,7 \\
\hline T2: $43 \mathrm{~kg}$ composto/planta & 29 & 21 & 1,9 & 1,5 & 32 & 21 & 9 & 11 & $2,8 \mathrm{~b}$ & 3,8 & 2,5 & 1,5 \\
\hline T4: $129 \mathrm{~kg}$ composto/planta & 30 & 22 & 2,0 & 1,5 & 30 & 21 & 9 & 12 & $3,3 \mathrm{ab}$ & 4,0 & 2,4 & 1,5 \\
\hline T5: $172 \mathrm{~kg}$ composto/planta & 30 & 21 & 2,1 & 1,4 & 31 & 22 & 9 & 13 & $3,4 \quad \mathrm{a}$ & 4,1 & 2,6 & 1,6 \\
\hline Médias & 30 & 21 & 2,0 & 1,5 & 31 & 21 & 9 & 12 & 3,2 & 4,0 & 2,5 & 1,6 \\
\hline$\overline{C V}(\%)$ & 3 & 8 & 4 & 6 & 4 & 10 & 6 & 9 & 9 & 13 & 7 & 20 \\
\hline
\end{tabular}

Médias seguidas por letras distintas na coluna diferem, pelo teste de Tukey, a 5\% de probabilidade.

* Fonte: Raij et al. (1997) - Boletim Técnico 100. 
TABELA 2 - Teores médios de micronutrientes em folhas de bananeira 'Prata-Anã', no florescimento e na colheita dos frutos (mg kg $\left.{ }^{-1}\right)$.

\begin{tabular}{|c|c|c|c|c|c|c|c|c|c|c|}
\hline \multirow[t]{2}{*}{ Tratamentos } & \multicolumn{2}{|c|}{ Boro } & \multicolumn{2}{|c|}{ Cobre } & \multicolumn{2}{|c|}{ Ferro } & \multicolumn{2}{|c|}{ Manganês } & \multicolumn{2}{|c|}{ Zinco } \\
\hline & Flor. & Colh. & Flor. & Colh. & Flor. & Colh. & Flor. & Colh. & Flor. & Colh. \\
\hline T1: 0 kg composto/planta & 46 & 35 & 8 & - & 172 & 163 & 1044 & 2820 & 11 & 16 \\
\hline T2: $43 \mathrm{~kg}$ composto/planta & 56 & 33 & 7 & - & 183 & 164 & 1058 & 2386 & 10 & 16 \\
\hline T4: $129 \mathrm{~kg}$ composto/planta & 54 & 37 & 8 & - & 164 & 211 & 1063 & 3018 & 11 & 15 \\
\hline T5: $172 \mathrm{~kg}$ composto/planta & 51 & 39 & 7 & - & 194 & 214 & 997 & 2672 & 11 & 15 \\
\hline Médias & 54 & 36 & 7 & - & 182 & 189 & 1064 & 2685 & 11 & 15 \\
\hline CV (\%) & 26 & 16 & 10 & - & 49 & 21 & 22 & 24 & 8 & 18 \\
\hline
\end{tabular}

Médias seguidas pelas mesmas letras na coluna não diferem, pelo teste de Tukey, a 5\% de probabilidade.

* Fonte: Raij et al. (1997) - Boletim Técnico 100.

e na colheita dos frutos, não mostraram diferença entre os tratamentos (doses de composto), Verificou-se, no entanto, uma tendência de elevação desses teores entre o período compreendido do florescimento à colheita, uma vez que o cálcio não é translocado das folhas para os frutos. Esses teores de cálcio encontravam-se dentro do padrão para a cultura (Raij et al., 1997), como pode ser observado na Tabela 1 e também concordando com outros autores (Jones Jr. et al., 1991; Robinson, 1986; Prezotti, 1992).

Os maiores teores foliares de magnésio, no momento do florescimento $\left(3,4 \mathrm{~g} \mathrm{~kg}^{-1}\right)$, foram encontrados no tratamento que recebeu a maior dose de composto (172 kg/ planta), mostrando que este composto, utilizado como fonte de adubo, é um bom fornecedor deste nutriente. Já na colheita dos frutos, os teores de magnésio nas folhas não diferiram entres as doses de composto (Tabela 1), apresentando em média 4,0 $\mathrm{g} \mathrm{kg}^{-1}$, teor este superior aos encontrados no momento do florescimento, que estava em média $3,2 \mathrm{~g} \mathrm{~kg}^{-1}$, sendo que em ambas as coletas os teores estavam dentro do padrão.

Os teores de enxofre nas folhas não foram influenciados pelos tratamentos, apresentando em média $2,5 \mathrm{~g} \mathrm{~kg}^{-1}$ no florescimento e $1,6 \mathrm{~g}$ $\mathrm{kg}^{-1}$ na colheita, observando-se, pela Tabela 1, que houve diminuição dos teores de enxofre nas folhas devido à translocação deste nutriente das folhas para os frutos. Os níveis de enxofre apresentavam-se próximos do limite inferior da faixa compreendida como adequada, que varia de 2,5 a 8,0 $\mathrm{g} \mathrm{kg}^{-1}$ (Raij et al., 1997), uma vez que não foi adicionada outra fonte de nutriente que o contivesse.

De maneira geral, os tratamentos não influenciaram significativamente nos teores foliares de micronutrientes, como pode ser observado na Tabela 2. Isso mostra que a concentração de micronutrientes em compostos orgânicos, em especial o utilizado neste trabalho, é relativamente baixa, sendo que, em algumas situações, é necessária a aplicação adicional de outros micronutrientes, como ocorreu com o boro.

O boro foi um micronutriente que apresentou queda em seus teores nas folhas, no período do florescimento até a colheita, passando em média de 54 para $36 \mathrm{mg} \mathrm{kg}^{-1}$, como pode ser observado na Tabela 2 . Tanto no florescimento como na colheita, as folhas apresentaram teores de boro acima do padrão para a cultura no Estado de São Paulo, mas visualmente algumas plantas apresentaram folhas com sintomas característicos de deficiência. Contudo, de acordo com resultados encontrados por Robinson et al. (1986) e Jones Jr. et al. (1991), o teor de boro nas folhas estava dentro da faixa que preconizam como adequada. $\mathrm{O}$ alto teor de boro encontrado nas folhas pode ser explicado pela aplicação via solo desse nutriente, como é recomendado para a cultura (Raij et al., 1997).

Os teores foliares de cobre no florescimento encontravam-se adequados, e os teores de ferro mantiveram-se estáveis do florescimento até a colheita (Tabela 2), sendo que estes teores se encontravam dentro da faixa adequada para a cultura.

Houve um acúmulo de manganês nas folhas de bananeira (Tabela 2), sendo que, no período do florescimento das plantas, os teores de manganês se encontravam adequados $\left(1.064 \mathrm{mg} \mathrm{kg}^{-1}\right)$. Com o transcorrer do ciclo da cultura, este elemento passou a se acumular nas folhas, apresentando teores um pouco acima do padrão $\left(2685 \mathrm{mg} \mathrm{kg}^{-1}\right)$, sem, contudo, as plantas apresentarem sintomas visuais de toxidez, pois, de acordo com resultados obtidos por Silva et al. (2003), altos teores de manganês em folhas de bananeira podem causar queda de produção.

Os teores foliares de zinco não foram influenciados pelas doses do composto aplicadas ao solo, porém houve pequena elevação em sua concentração nas folhas entre o florescimento e a colheita, sendo que, em ambas as coletas, os teores deste micronutriente estavam abaixo do padrão da cultura (Tabela 2).

Os parâmetros de produção avaliados, como peso do cacho, número de frutos por cacho, número de pencas por cacho, peso da $2^{\mathrm{a}}$ penca, número de frutos na $2^{\mathrm{a}}$ penca, comprimento e diâmetro de frutos, não mostraram diferença significativa para os tratamentos, apresentando como médias $16,4 \pm 2,1 \mathrm{~kg} ; 123 \pm 11$ frutos; $9,1 \pm 0,5$ penca; $2,00 \pm 0,28$ $\mathrm{kg} ; 15,8 \pm 1,0$ fruto; $13,0 \pm 0,6 \mathrm{~cm} ; 36,3 \pm 1,24 \mathrm{~mm}$. Considerando os dados médios de peso de cacho, verificou-se produtividade média de 26,24 t/ha. Essa produtividade da bananeira 'Prata-Anã' superou a média nacional, que está em 12,17 t/ha (FAO, 2004).

\section{CONCLUSÕES}

1. Os teores dos macronutrientes analisados em folhas de bananeira 'Prata-Anã' não foram influenciados pelo incremento de doses de composto orgânico.

2. Os teores de macronutrientes foliares apresentaram tendência de queda entre o florescimento e a colheita, com exceção do $\mathrm{Ca}$ e $\mathrm{Mg}$, que tenderam a se acumular nas folhas.

3. Os teores de potássio foliares verificados durante o florescimento encontravam-se pouco abaixo dos padrões para a cultura e, mesmo assim, não apresentaram sintomas de deficiência ou queda de produção.

4. Os teores de micronutrientes não foram influenciados pela adubação orgânica, permanecendo numa faixa considerada adequada para a cultura, exceção ao boro, que mostrou sintomas de deficiência, mesmo seus teores foliares encontrando-se elevados.

5. Os teores de potássio, considerados adequados para a bananeira 'Prata-Anã', podem ser inferiores aos padrões atualmente adotados para a cultura.

\section{AGRADECIMENTOS}

À FAPESP - Fundação de Ampara à Pesquisa do Estado de São Paulo, pela concessão da bolsa de mestrado, processo n ${ }^{\circ}$ 02/11484-4.

\section{REFERÊNCIAS}

BORGES, A.L.; OLIVEIRA, A.M.G. Nutrição Calagem e Adubação. In: CORDEIRO, Z.J.M. Banana. Produção: aspectos técnicos. Brasília: Embrapa Comunicação para Transferência de Tecnologia, 2000. p.47- 
59. (Frutas do Brasil, 1).

BORGES, A.L.; SILVA, T.O. da; CALDAS, R.C.; ALMEIDA, I.E. de A. Adubação nitrogenada para bananeira terra (Musa sp. AAB, subgrupo Terra). Revista Brasileira de Fruticultura, Jaboticabal, v.24, n.1, p.189-193, 2002.

CARVALHO, J.G. de; PAULA, M.B. de; NOGUEIRA, F.D. Nutrição e adubação da bananeira. A cultura da bananeira. Informe agropecuário, Belo Horizonte, n.133, p. 20-32, 1986.

CUNHA, A.R.; KLOSOWSKI, E.S.; GALVANI, E.; SCOBEDO, J.F.; MARTINS, D. Classificação climática para o município de BotucatuSP, segundo Koppen. In: SIMPÓSIO EM ENERGIA NA AGRICULTURA, 1., 1999, Botucatu. Anais... Botucatu: Faculdade de Ciências Agronômicas, Universidade Estadual Paulista, 1999. p.487-491.

EMBRAPA. Centro Nacional de Pesquisa de Solos. Sistema brasileiro de classificação de solos. Rio de Janeiro: EMBRAPA/SOLOS, 1999. $412 p$.

FAO-FOOD AND AGRICULTURE ORGANIZATION. Disponível em: $<$ http://faostat.fao.org/ faostat>. Acesso em: 16 nov. 2004.

FONTES, P.S.F; CARAVALHO, A.J.C. de; CEREJA, B.S.; MARINHO, C.S.; MONNERAT, P.H. Avaliação do estado nutricional e do desenvolvimento da bananeira 'Prata-anã' (Musa spp.) em função da adubação nitrogenada. Revista Brasileira de Fruticultura, Jaboticabal, v.25, n.1, p.156-159, 2003.

GOMES, E.M. Crescimento e produção de bananeiras 'Prata-anã' e 'Maçã' fertirrigadas com potássio. 2004. 76f. Tese (Doutorado em Agronomia / Irrigação e Drenagem)- Faculdade de Ciências Agronômicas, Universidade Estadual Paulista, Botucatu, 2004.

GUERRA, A.G. Fertirrigação com nitrogênio e potássio utilizando sistema de irrigação por microaspersão na cultura da bananeira 'Prata-anã'. 2001. 69f. Tese (Doutorado em Agronomia / Produção Vegetal)-Faculdade de Ciências Agrária e Veterinárias, Universidade Estadual Paulista, Jaboticabal, 2001.

JONES JR., J.B.; WOLF, B.; MILLS, H.A. Plant analyses handbook: a practical sampling, preparation, analyses and interpretation guide. Athens (USA): Micro-Macro Publishing, 1991.213p.

LAHAV, E.; TURNER, D.W. Banana nutrition. Bern: International Potash Institute, 1983. 62p. (Bulletin, 7).
MALAVOLTA, E. Potássio, magnésio e enxofre nos solos e culturas brasileiras. Piracicaba: Franciscana, 1979. 92p. (Boletim Técnico, 4).

MALAVOLTA, E.; VITTI, G.C.; OLIVEIRA, S.A. de. Avaliação do estado nutricional das plantas: princípios e aplicações. 2.ed. Piracicaba: Potafos, 1997.319p.

MARTIN-PRÉVEL, P. Bananier. In : MARTIN-PRÉVEL, P., GAGNARD, J., GAUTIER, P. (Eds.) L'analyse végétale dans le contrôle de l'atation des plantes tempérées et tropicales. Paris: Tec \& Doc, 1984. p. 715-751.

MARTIN-PREVÉL, P. Echantillonnange du bananier por l'analyse foliare; cons'equences des differences de techiniques. Fruits, Paris, v.32, n.3,p.151-166, 1977.

MOREIRA, R.S. Banana: teoria e prática de cultivo. Campinas: Fundação Cargill, 1987.335p.

PREZOTTI, L.C. Recomendação de calagem e adubação para o Estado do Espírito Santo: $3^{a}$ aproximação. Vitória:EMCAPA, 1992. 73p. (Circular Técnica, 12).

RAIJ, B. van; CANTARELLA, H.; QUAGGIO, J.A.; FURLANI, A.M.C. (Ed.). Recomendações de adubação e calagem para o Estado de São Paulo. 2.ed. Campinas: Instituto Agronômico/Fundação IAC, 1997. 285p. (Boletim Técnico, 100).

RIBEIRO, A.C.; GUIMARÃES, P.T.G.; ALVAREZ, V.H. Recomendações para o uso de corretivos e fertilizante em Minas Gerais: $5^{\text {a }}$ aproximação. Viçosa: CFSEMG, 1999.359p.

ROBINSON, J.B. Fruits, Vines e Nuts. In: REUTER, D.J.; ROBINSON, J.B. (Ed.). Plant analyses: an interpretation manual. Melbourne: Inkata Press, 1986. p.120-147.

SILVA, J.T.A. da; BORGES,A.L.; CARVALHO, J.G.; DAMASCENO, J.E.A. Adubação com potássio e nitrogênio em três ciclos de produção da bananeira cv. Prata-anã. Revista Brasileira de Fruticultura, Jaboticabal, v.25, n.1, p.152-155, 2003.

TEIXEIRA, L.A.J. Adubação nitrogenada e potássica em bananeira 'Nanicão' (Musa AAA subgrupo Cavendish) sob duas condições de irrigação. 2000. 130f. Tese (Doutorado em Agronomia / Produção Vegetal). Faculdade Ciências Agrárias e Veterinárias, Universidade Estadual Paulista, Jaboticabal, 2000. 